\title{
O papel estratégico da crítica na formação do pensamento cinematográfico ${ }^{1}$
}

\section{The strategic role of criticism in shaping film theory}

Ismail Xavier ${ }^{2}$

1 Artigo editado a partir do texto básico da Palestra de encerramento do "XXI Encontro da SOCINE - o estado da crítica", 17 a 20 de outubro de 2017, Universidade Federal da Paraíba, João Pessoa. 


\section{Resumo}

Este artigo focaliza três momentos significativos da reflexão e do debate sobre o cinema no século $X X$, a fim de caracterizar formas de articulação entre o exercício da crítica em periódicos e a produção escrita ligada a núcleos de formação da cinefilia, como os cineclubes, e a centros de formação e pesquisa, como as cinematecas e, notadamente a partir dos anos 1960 , as universidades.

Palavras-chave

Cinema, cinefilia, cineclube, cinemateca, crítica cinematográfica.

\section{Abstract}

This article focuses on three relevant moments of the reflection and the debate on the $20^{\text {th }}$ century cinema. Our intention is to identify the ways by which the practice of criticism in news journals meets the written production coming from cinephile centers, movie clubs, educational and research centers, such as film libraries and notably universities after the 60's.

\section{Keywords}

Cinema, cinephilia, movie clubs, movie libraries, movie critique. 
A experiência da crítica suscita um leque enorme de questões igualmente centrais e de grande interesse que podemos trazer para a nossa reflexão. Dentro da dinâmica que envolve o diálogo dos filmes com os seus diferentes públicos, diálogo sem o qual o percurso de cada obra não se completa, a crítica constitui um elo estratégico da cultura cinematográfica em sua dimensão estética, social e política, dada a sua condição de diálogo direto com as obras na qual a síntese de informação, a análise da relação entre o filme e a experiência humana colocada em pauta e os juízos de valor compõem uma referência que, num cômputo geral, pode ter implicações de longo prazo.

Há uma variedade de formas nesta relação entre a crítica e os filmes, de um lado, e entre a crítica e seus leitores, do outro. De imediato, pensamos no exercício da crítica nos jornais e nas revistas semanais, modalidade que inclui nos dias de hoje muitas revistas digitais para leitura online e também os blogs assinados por críticos. Nesses casos, é mais incisivo o desafio da resposta primeira aos filmes no momento de sua estreia, um corpo a corpo com o presente imediato que se expressa em artigos concisos que demandam uma escrita aguda na argumentação e que procura evitar o jargão de especialista - traços que compõem um enorme desafio no plano do estilo e da escolha de uma estratégia para a abordagem dos filmes. Dessa escolha decorre o que os leitores identificam ao longo do tempo como o estilo de determinado crítico.

Em nossa reflexão, ao lado dessa modalidade, podemos incluir a crítica exercida em periódicos publicados mensalmente - como é o caso bem conhecido dos Cahiers du Cinéma - ou mesmo duas a quatro vezes por ano, incluindo revistas que tiveram e têm importante papel nesse diálogo com o presente da produção, mas reservam mais espaço - este "mais" será tanto maior quanto mais larga for a periodicidade - para matérias de feitio variado. Essas matérias, é bom frisar, não estão excluídas dos jornais e revistas de resposta mais imediata, como retrospectos, análises comparativas de filmes agrupados sob variados critérios, incursões na história do cinema e textos mais teóricos, mas não compõem o que é mais característico ao jornal diário, sendo mais próprio acontecerem nos suplementos de fim de semana. 
No caso de revista de larga periodicidade, um bom exemplo da convivência de críticos, entre eles Enéas de Souza, e professores universitários em seu corpo editorial é a revista Teorema publicada em Porto Alegre, semestral, com ampla gama de colaboradores de variadas procedências.

Aponto essa conhecida diversidade das formas de publicação da crítica em distintos contextos, cada qual com a sua feição específica, sabendo de sua permeabilidade na arregimentação de editores e articulistas, pois são muitos os exemplos de colegas professores que têm ou tiveram participação em revistas não acadêmicas, ou mesmo em jornais, embora nestes casos seja raro o trabalho contínuo. Por outro lado, muitos críticos ministram cursos de cinema, colaboram em revistas trimestrais ou quadrimestrais e é comum a autoria de livros que, não sendo coletâneas de críticas publicadas em jornais ou revistas, trazem um ensaio crítico em torno de um núcleo temático, resultado de pesquisa. Os exemplos são muitos e a título de referência, cito apenas $A$ ponte clandestina: teorias do cinema na América Latina, de José Carlos Avellar (1995), que foi crítico do Jornal do Brasil por muitos anos.

Enfim, muitos de nós, com ênfase num polo ou no outro, já vivemos e vamos viver o que há de comum e de diferente entre a atividade mais regular da crítica e a escrita de livros ou de um ensaio mais longo e mais abrangente no seu enfoque. Em resumo, não esqueçamos essas diferenças de condições de trabalho e de público leitor, nem tampouco o trânsito de muitos de nós por elas.

Coloco aqui de início essa permeabilidade vivida na relação entre esses terrenos porque, como anuncia o título desta fala, estou interessado em citar conjunturas históricas que exatamente evidenciaram a articulação entre os vários contextos de reflexão e produção textual sobre cinema, da resenha crítica num diário à produção de livros, ambas já consolidadas por todo um século que, em um período mais recente, veio incluir a bibliografia construída no mundo da pesquisa acadêmica, seja pela mão da historiografia do cinema ou pelas distintas formas de composição de ensaios críticos, sejam análises de conjunto 
de um gênero (como o documentário contemporâneo) ou estudos comparativos envolvendo um grupo de filmes a partir de um eixo temático ou formal.

A ideia é trabalhar momentos nucleares nos quais se fez nítido o papel estratégico da crítica na formação de um pensamento cinematográfico de ressonância na história e na teoria do cinema. Destaco três núcleos que evidenciaram, de formas variadas, essa articulação: no primeiro, comento a crítica em sua interação com o cineclubismo; no segundo, a crítica em sua interação com as cinematecas; no terceiro, a crítica em sua interação com as universidades, dentro de um processo que, iniciado nos anos 1960, se expandiu a partir dos anos 1970. A cada nova etapa, os pontos focais da formação, já presentes nas fases anteriores, foram se somando ao novo parceiro, até formarem a imensa rede de produção de pensamento e de circulação de ideias bem próprias ao nosso presente, rede que complica bastante a configuração do campo apta a esclarecer o papel de cada um desses focos.

A configuração atual demanda pesquisas no plural, pois é grande o desafio. Nesta exposição, não trago algo que seja resultado de estudo sistemático; trago apenas uma reflexão preliminar voltada para experiências que evidenciaram, de formas variadas, esta interação que interessa aqui sublinhar a partir da dinâmica própria a três momentos históricos, tomados aqui como referência geradora de parâmetros de análise.

\section{A crítica e os cineclubes}

O primeiro núcleo a lembrar se constituiu na relação entre a crítica e o cineclubismo num momento fundamental, ou seja, nos primórdios da reflexão sobre o cinema que, em verdade, se consolidou a partir dessa interação. Como se sabe, foi com a criação de cineclubes que a primeira cinefilia ganhou corpo, esta que teve enorme impacto na crítica e na teoria. Basta lembrar que Riccioto Canudo, crítico e um dos pioneiros do cine-clubismo no começo do século XX com a fundação do Clube dos amigos sétima arte, foi um grande animador de sessões, nas quais projetava trechos de filmes e solicitava a seu público que prestasse atenção apenas à dimensão plástico-imagética do cinema, não Ihes dando chance 
de serem capturados pelo desenvolvimento do melodrama ou da comédia que traziam aqueles filmes curtos (expressão anacrônica) na virada da primeira para a segunda década do século XX. A expressão "sétima arte", sendo sua invenção, foi cunhada a partir de sua posição estética peculiar que está bem expressa no célebre Manifesto das sete artes publicado em 1911, em Paris ${ }^{3}$. Era o momento em que começava a se configurar o comentário aos filmes em jornais e revistas, o qual se expandiu com força nos anos seguintes para compor experiência crítica de juízos de valor que, em sua variedade de critérios, compunha um polo mediador entre os filmes e uma parcela do público. Neste contexto de consolidação da crítica de cinema, foi se afirmando toda uma variedade de posturas e juízos de valor, mas o segmento que ganhou maior notoriedade histórica foi o que se fez núcleo fundamental da primeira teoria do cinema. Em parte, afinado às ideias de Canudo, esse segmento, formado por críticos e cineastas, trazia um variado espectro de posturas, algumas menos radicais na adoção do princípio da "especificidade cinematográfica", tal como definido no sistema estético do Manifesto (MACEDO, 1959). Segundo este, a condição para o cinema despontar como síntese das artes, era a de assumir sua vocação de arte plástico-rítmica, superando sua condição de veículo para a encenação de melodramas e comédias, via de regra estórias consideradas elementares: foi a primeira diatribe do cinéfilo contra o chamado "teatro filmado", e das vanguardas contra o cinema narrativo-dramático. Essa primeira postura crítica celebrou o cinema como técnica promissora, emblema da modernidade, e se fez no atrito, dia a dia, com os filmes que os críticos e cineastas ligados à vanguarda atacavam, com maior ou menor veemência. Não é o caso de configurar aqui todo o quadro da época, e lembro apenas Louis Delluc, crítico e cineasta, sem esta recusa menos incisiva do narrativo-dramático que, afinal, marcou os seus próprios filmes; e Jean Epstein, crítico e cineasta que criou o corpo teórico mais robusto hoje reunido em livros, mas que foi em grande parte exposto em artigos como o que dedicou à noção de fotogenia, central na teoria 
da vanguarda ${ }^{4}$. A primeira referência à fotogenia foi de Louis Delluc, em 1919, mas Epstein é quem lapidou o conceito numa conferência proferida em 1923 e que foi publicada no seu livro Le cinématographe vu de l'Etna, de $1926^{5}$.

Jean Epstein escrevia na revista Esprit Nouveau ${ }^{6}$ que se ocupava das artes, mas com maior ênfase à literatura, e vale lembrar aqui um texto seu fundamental "A poesia e o novo espírito da inteligência", publicado nessa revista em 1921, no mesmo ano em que ele publicava o livro Bonjour cinema (EPSTEIN, 1921), consolidando essa afinidade entre o novo espírito da poesia e o nascimento do cinema como arte. Sabemos, ainda, o quanto aquele debate teórico dos anos 1920 envolveu artistas plásticos, poetas, críticos e realizadores.

A mesma relação entre os poetas e a crítica de cinema se deu no campo do surrealismo, cuja "teoria do cinema", nada simpática aos escritos de Epstein, foi exposta pelo poeta Robert Desnos em artigos de revistas (DESNOS, 1966). É possível, ainda, relacionar o caso ao contexto da crítica e teoria na União Soviética, que viveu dinâmica semelhante, na qual se destacaram textos que criaram conceitos fundamentais no próprio movimento de afirmação polêmica de uma poética inovadora, tal como aconteceu no caso dos construtivistas, S.M. Eisenstein e Dziga Vertov.

Neste quadro aqui resumido, uma referência aos Estados Unidos encontra uma conexão de mesmo tipo entre os poetas e a reflexão sobre cinema, como aconteceu com Vachel Lindsay que, no momento em que a critica de cinema já havia tomado impulso, publicou The art of the moving picture em $1915^{7}$, livro escrito na época em que, na França, a noção de fotogenia tomava maior impulso, tendo em Epstein seu principal formulador. O dado, digamos, original, nos escritos sobre cinema nos Estados Unidos, foi o livro teórico escrito por um professor 
universitário, publicado originalmente em 1916: The photoplay: a psychological study, de Hugo Munsterberg (1970), professor de psicologia na Universidade de Harvard. Trata-se de um extraordinário pequeno tratado de estética do cinema pensada em conexão com sua atividade de professor de psicologia.

A partir do referencial construído pelas vanguardas, ocorre uma nítida articulação entre o cineclubismo e o mundo dos artistas plásticos, poetas e cineastas, daí se desdobrando as teorias. Estas se articulam a juízos de valor, à crítica do gosto e à incidência, no campo do cinema, de um ideário muito claro: a cobrança de originalidade (feita ao cineasta) e a defesa da especificidade do cinema como arte plástica de formas em movimento, a baliza maior da valorização das obras. Vivemos até hoje este primado da originalidade e da invenção formal como valor por excelência, algo que se construiu naquele espírito das vanguardas de um século atrás.

Escolhi essa experiência dos anos $1910-20$ pelo seu teor inaugural e sua incidência na reflexão desenvolvida ao longo da história do pensamento cinematográfico, mesmo quando ela foi objeto de crítica da parte de quem assumia outros valores como, por exemplo, os defensores do cinema industrial, narrativo-dramático. Em particular, a passagem do cinema mudo para o sonoro definiu um momento de grande polaridade que alterou o quadro da teoria e, nos anos 1930, um novo contexto produziu nova reflexão, o que nos leva ao segundo momento que interessa aqui comentar.

Antes, para estabelecer o gancho entre esses dois momentos expressos no percurso do crítico, lembro um sugestivo exemplo que nós é muito próximo: o de Paulo Emilio Salles Gomes e sua formação como crítico, historiador e pesquisador: vale lembrar sua experiência na França entre 1937 e 1939, quando se tornou um cinéfilo nas sessões da Cinemateca Francesa, levado por Plínio Sussekind Rocha, ex-membro fundador do Chaplin Club do Rio de Janeiro, cujo jornal, $O$ Fan, publicara, entre 1929 e 1931, textos que se situam entre as melhores críticas de cinema escritas da primeira metade do século XX no Brasil. Nesta conexão biográfica entre Plínio Sussekind e Paulo Emilio, está simbolizada a passagem 
que interessa focalizar: o momento em que, aos cineclubes, se somaram as cinematecas como elemento decisivo da formação para a militância do crítico.

\section{A crítica e as cinematecas}

Esta passagem para o nosso segundo momento se dá nos últimos anos da década de 1930, quando entram em cena as cinematecas. A Francesa, criada em 1936, saída do cineclube Cercle du cinéma, foi por muitos anos a instituição líder dessa militância pela preservação da memória e pela exibição de acervos como vetor da formação de público, de críticos e de novos cineastas, além de foco impulsionador de uma historiografia do cinema lastreada em ampla documentação disponível.

A par deste papel nuclear, devo lembrar que as cinematecas entram em cena num momento de reavaliação dos caminhos do cinema dentro de uma nova conjuntura cultural e política, momento cuja figura chave na consolidação de um novo paradigma, além de cineclubista militante, foi um intelectual que escreveu parte substancial de sua criação teórico-crítica em revistas: falo de André Bazin, gigante da crítica que encarna um dos casos mais extraordinários de uma teoria construída no corpo a corpo com os filmes, base de sua defesa de uma forma de cinema que ele identificou em Jean Renoir, Orson Welles e no neorrealismo, para ele artífices de um avanço decisivo em nova direção que ele cunhou de realista, dentro de uma acepção nada elementar de realismo que cunhou a partir de um diálogo com a fenomenologia (BAZIN, 2018). De fato, Maurice Merleau-Ponty escreveu sobre o cinema em geral, notadamente no artigo "O cinema e a nova psicologia" (MERLEAU-PONTY, 1969), a partir de conferência dada no IDHEC (Institut des Hautes Études Cinématographiques), em 1945, mas a especificação feita por Bazin e sua elaboração crítico-teórica foram construídas a partir daquela percepção aguda do estilo, em particular do novo estilo cujo ícone maior foi o plano longo, no limite, o plano-sequência. Configura-se, a partir daí, claro que com muitas outras questões acopladas e discutidas, a noção de cinema moderno (BAZIN, 2018). 
Um dado a acentuar na articulação do campo crítico-teórico com as cinematecas é seu lugar como centro de formação de cinéfilos que passaram a viver o impacto gerado pelo maior e mais sistemático acesso à história que possibilitou uma erudição do olhar e da escuta cultivada no contato direto, e digamos simultâneo, com filmes de todas as décadas; o cotejo entre o passado e o presente se torna algo mais rotineiro, incentivando um novo tipo de espectador-criador. Desse processo, o exemplo mais célebre, experiência notável com implicações de longo prazo, não só na crítica mas também na criação de um novo cinema, foi a da formação, na Cinemateca Francesa, dos futuros "jovens turcos" dos Cahiers du Cinéma, como foi chamado o grupo de Godard, Truffaut, Rivette, Chabrol e seus amigos nos anos 1950, quando colaboravam com a revista fundada por André Bazin em 1951. Radicais na defesa de suas posições e polemistas, os jovens turcos trouxeram a primeiro plano a questão da autoria no cinema, pensada inclusive no contexto da produção hollywoodiana e, quando passaram à realização, tiveram papel chave na história do cinema moderno. Enfim, foram uma dominante nos anos 1960.

Não por acaso, Henri Langlois, o criador e por muitos anos diretor da Cinemateca Francesa, é a figura que recebe a homenagem de Godard num dos episódios de sua série de vídeos que montaram as suas Histoire(s) du cinéma ao longo dos anos 1980. Homenagem enfática, a celebrar da figura do pai.

Naquele novo contexto dos anos 1940-1960, a produção de livros de história e teoria do cinema se diversifica, inclusive com reflexões sobre a história da crítica, definindo uma multiplicidade de referências já consolidadas no momento em que as universidades vieram participar deste jogo. Enfim, como sabemos, a crítica e a teoria já tinham uma longa história, com suas coordenadas e muitos textos básicos já estabelecidos quando as universidades entraram em cena de forma mais incisiva, compondo um novo leque de experiências que se consolidou de forma mais definitiva ao longo dos anos 1970. No momento em que nos aproximamos da nossa conjuntura, a bibliografia sobre cinema se avolumou e foram se multiplicando as revistas, os congressos e os livros. 


\section{A crítica e as universidades}

Nesta reflexão preliminar, começo com o comentário a três exemplos particulares que são sugestivos para quem quer pensar a articulação entre o exercício da crítica e a produção universitária. A partir desses três exemplos distintos em sua forma de evidenciar a interação entre crítica e universidade tomarei um caso de diálogo tenso entre críticos e pesquisadores como ponto de partida para um balanço final. Neste, farei observações que resumem uma posição pessoal na lida com essa experiência tal como ela se configura hoje.

O primeiro exemplo vem dos Estados Unidos, no período pós-Segunda Guerra Mundial: a partir de 1949, há a formação de um cinema de vanguarda que teve como ponto de convergência, em termos de reflexão, a revista Film Culture (1954-1996), onde Jonas Mekas, um de seus fundadores e um dos principais criadores desta nova vanguarda, teve sua militância crítica de enorme importância na convocação de novos cineastas que passaram a atuar nesse campo. O dado interessante é que o próprio dinamismo que alimentou o diálogo do cineasta experimental com o público - seja Maya Deren, Stan Brakhage, Hollis Frampton, Michel Snow ou Ken Jacobs - foram as exibições em universidades e galerias de arte, centros de exibição e debate de filmes em 16 mm que compunham um cinema afinado às artes visuais, a qual permanecia invisível para o grande público. De certo modo, essa experiência ganhou mais ampla visibilidade quando um artista pop star como Andy Warhol entrou na cena para fazer seus filmes, Chelsea Girls e Empire State Bilding, entre outros, gerando polêmica com o mesmo teor daquela que a pop art havia gerado no campo das artes visuais, em sua ironia ao Action Painting de Jackson Pollock, De Kooning e todo um grupo de artistas engajados nessa experiência fundamental do pós-guerra. Falava-se de um cinema underground, mas muito pouco se conseguia ver. Mesmo lá nos Estados Unidos tal marginalidade se constituiu em condição vivida por décadas, a menos nos campi universitários, nos museus, nas galerias de arte e nos cineclubes. Mekas se tornou o diretor de uma cinemateca especializada na guarda e exibição desses filmes e outros de varias épocas, incluídos os filmes de Dulac, Epstein, Eisenstein 
e Vertov, que foram inseridos no elenco do que esta vanguarda denominou de Cinema Essencial: falo do Anthology Film Archives, de Nova York, Anthology cuja extraordinária biblioteca era dirigida por P. Adams Sitney, professor e pesquisador da New York University, autor do livro clássico Visionary Cinema (SITNEY, 1974). Na virada dos anos 1960 para os 1970, a NYU havia se tornado uma caixa de ressonância desse cinema e tinha como professores figuras como Annette Michelson, que escreveu os principais ensaios sobre este cinema em revistas como Artforum. Nos anos 1970, vieram Sitney (doutorado na Yale University) e Noel Carrol (doutorado na própria NYU, orientado por Annette Michelson). Noel teve artigos sobre as vanguardas publicados na Artforum, depois alterou a tônica de sua reflexão teórico-crítica quando se deslocou para a Universidade de Wisconsin e passou a trabalhar em parcerias com David Bordwell e Edward Branigan, entre outros professores universitários que impulsionaram a teoria do cinema narrativo.

O segundo exemplo configura de forma bem nítida o que é próprio à pesquisa historiográfica e seu quadro teórico mais específico, que exige hoje as condições oferecidas pelas universidades e cinematecas para se desenvolver. Trata-se da pesquisa voltada para o cinema do período entre 1895 e a consolidação do cinema narrativo nas salas de cinema: o chamado early cinema ou cinéma des premiers temps ou primeiro cinema, este que Tom Gunning e André Gaudreault chamaram de "cinema de atrações" para diferenciá-lo, em seus princípios e estratégias de comunicação, do cinema narrativo. Esta pesquisa definiu um caso paradigmático da presença da universidade, a partir do qual podemos avançar uma hipótese: quanto mais distante no tempo o objeto de estudo, mais clara a tendência de ele requerer um processo de produção do conhecimento que requer as condições da universidade. Esse é um trabalho que se desenvolveu no mundo acadêmico, conduzido por professores universitários, com respostas na Europa vindas de figuras como Jacques Aumont, já professor da Universidade de Paris 3 e Thomaz Elsaesser, professora da Universidade de Amsterdam) (ELSAESSER; BARKER, 1990). Esses são exemplos que caracterizam muito bem a presença essencial das cinematecas e as condições de pesquisa oferecidas pelas universidades, um 
dado bem próprio ao campo da historiografia. Nesse campo, a formulação de novos métodos de pesquisa é um fenômeno que depende dos arquivos e dos pesquisadores. É interessante citar uma experiência que testemunha muito bem a passagem da primeira historiografia dos tempos de Georges Sadoul, Guido Aristarco e Jean Mitry, para esta de cunho universitário: falo da experiência de Jay Leyda, figura extraordinária que, nos anos 1950-1960, quando trabalhava na Cinemateca Francesa, pesquisou e escreveu o clássico Kino, uma história do cinema russo e soviético, que reunia pesquisas iniciadas quando estava na Rússia, como aluno de S.M. Eisenstein nos anos 1930, até que a perseguição do stalinismo a Eisenstein - "o cosmopolita" - levou a que todos os seus estudantes estrangeiros fossem embora da União Soviética. Num segundo momento, nos anos 1960, fez pesquisa na China e escreveu um estudo sobre o cinema chinês, ambas as pesquisas tendo sido desenvolvidas fora do mundo acadêmico (LEYDA, 1960, 1972). Um trabalho de erudito e extraordinário pesquisador que alterou suas condições de trabalho somente em seu terceiro momento, quando, de volta aos Estados Unidos, tornou-se professor universitário. Nos anos 1970, na New York University, coordenou um grupo de pesquisa formado por alunos de pós-graduação no chamado Seminário Griffith, atividade que se desdobrou, porque era necessário, num estudo mais geral do early cinema, contexto no qual se formaram figuras como Tom Gunning e Charles Musser, entre outros historiadores do cinema hoje bem conhecidos.

O terceiro exemplo trata de outra forma de articulação entre a pesquisa universitária e o contexto da crítica. A França é, sem dúvida, o melhor terreno para explorar essa questão, um caso especial quando comparado a outros países.

A partir de 1964, tem-se a instauração da semiologia do cinema, com a figura de Christian Metz. É o momento estruturalista, um impulso em direção à ciência a partir de uma incorporação de conceitos da linguística de Ferdinand de Saussure. A aplicação metódica de novos conceitos anunciava um momento mais "científico", com o primado de um esquema operatório que assumia a feição mais nítida de um método rigoroso - para alguns, superação de uma fase mais 
"ideológica" e mergulho mais decisivo nas questões de método, rigor e conceitos claramente definidos.

O ponto a ressaltar aqui é o fato de Metz, na sua construção, dialogar bastante com a crítica - notadamente com Bazin. Nos desdobramentos do estruturalismo na teoria do cinema, veio o confronto com as posições polêmicas que marcaram a batalha entre os Cahiers du Cinéma (onde escreviam Jacques Aumont, Michel Marie, Jean Narboni e Jean-Louis Comolli, na sua fase pós-1968), e a revista Cinéthique, igualmente radical em sua recusa do cinema dominante no mercado (mesmo o moderno no sentido de Bazin e da nouvelle-vague), mas com posição distinta daquela dos Cahiers, gerando formulações polêmicas que foram repetidamente postas na arena, tendo muita coisa girado em torno da noção chave de "desconstrução" (emprestada de Jacques Derrida). Temos em 1969/70 um momento de debate acirrado em torno das formas de radicalização pensadas a partir do cinema de Godard, Georges Poulet e do casal Jean-Marie Straub e Danielle Huillet. Aqui é nítido o quanto a produção de teoria, notadamente no caso da lida com a noção de "dispositivo" nos escritos de Jean-Louis Baudry, marca a ascensão de um grupo de críticos que se encaminharia em seguida para a vida universitária. Alguns dos protagonistas desse debate depois se tornam professores universitários, passando a produzir ensaios críticos e livros teóricos, juntando-se a Raymond Bellour: é o caso de Jacques Aumont, Michel Marie, Jean-Louis Comolli e Jean-Louis Baudry, entre outros. Nesse caso, há uma produção teórica que se vale do percurso de cada teórico em particular, mas também há esse ponto comum no qual se vê a imbricação entre o percurso da crítica, esta num momento muito rico de formulações alimentadoras de polêmica, e o percurso de aclimatação dos debates no âmbito das opiniões teóricas daqueles autores nos quais o debate crítico alimentou a pesquisa, não sendo expulsos dela.

Nesse processo, há variantes na forma de articulação entre a crítica das revistas e a formulação de um pensamento teórico mais sistemático exposto em livros. Vou apenas me deter ao caso de Gilles Deleuze, filósofo e professor, um notável exemplo dessa articulação entre referenciais construídos pela crítica e 
a pesquisa teórica ligada à vida universitária. Quando, nos anos 1980, escreve dois livros fundamentais que estão articulados vivamente entre si - $A$ imagem movimento (1985) e A imagem tempo (1990) - Deleuze nos evidencia, ao longo das percucientes análises de filmes a partir das quais vai expondo sua teoria, a presença subjacente de uma história do cinema que não é, em princípio, tomada como eixo organizador da teoria - ele não está fazendo história, está escrevendo um capítulo da sua filosofia que faz desses livros citados um momento muito especial em que o cinema vai além de lugar de aplicação de uma teoria já pronta. O curioso nesse ensaio filosófico é a presença de um intenso diálogo com a revista Cahiers du Cinéma entre sua fundação (1951) e meados dos anos 1960. A partir de assídua leitura dos Cahiers, nota-se que a configuração que está bem clara nessa divisão em duas partes corresponde ao que a crítica da revista tinha formulado em termos da oposição entre cinema clássico e cinema moderno, não por acaso sendo o primeiro volume dedicado a análises de cineastas dos anos 1920 ao cinema clássico Hollywoodiano, incluindo os cineastas europeus da primeira vanguarda, Jean Epstein e S. M. Eisenstein. O segundo volume se constitui a partir da análise do cinema neorrealista. Com efeito, Deleuze (1985, 1990) cria uma teoria do cinema como capítulo importante da exposição de sua própria filosofia, de um modo que nenhum dos filósofos que escreveram sobre o cinema haviam feito. Nessa invenção onde estava implicada uma crítica ao establishment da teoria francesa (a sua crítica ao modelo da semiologia e do estruturalismo que matam justamente o Tempo como categoria constitui um marco de grandes implicações até hoje). O que vale destacar é que, como filósofo, não expulsou o cinéfilo que vivia dentro dele nem seu intenso diálogo com a crítica cuja incidência se fez nítida em passagens importantes de seu argumento.

Não surpreende que tenha escrito o prefácio do livro de Serge Daney, Ciné Journal, que reúne os textos que essa figura icônica da história dos Cahiers du Cinéma dos anos 1970-80 havia escrito na revista nos anos 1980 (DANEY, 1986). Daney é o crítico por excelência que tirou os Cahiers, em meados dos anos 1970, do que qualificou de teoricismo (fato que prontamente anunciou sua assunção 
da direção da revista), recolocando-a no trilho que havia construído desde a sua fundação e depois, insatisfeito com os rumos da revista, já na virada dos anos 1980 para os 1990, saiu e fundou a revista Trafic, com um corpo editorial que incluiu figuras de pesquisadores como Raymond Bellour, ao lado de ex-críticos dos Cahiers, como Sylvie Pierre.

Poderia ampliar os exemplos, mas está claro que meu interesse é sublinhar e evidenciar variadas formas de ajuste desses dois terrenos: escrever um artigo de revista acadêmica ou um livro envolve responder a demandas distintas quando comparadas com as demandas trazidas pelo exercício da crítica em jornais, e não falo em maior ou menor complexidade do texto, mas em situações que, nas suas diferenças, trazem desafios que lhe são próprios e envolvem a figura do escritor por inteiro, algo que se expressa na argumentação, no estilo, nos insights críticos e na tomada de posição, aí incluídos os juízos de valor que nos dois terrenos têm lugar, mesmo quando de modo bem distinto.

Fez-se a evocação desses três momentos de articulação entre a crítica e outros núcleos institucionais, de formação do pensamento cinematográfico. Procurou-se sublinhar a fecundidade do diálogo entre eles, algo não apenas produtivo, mas desejável, não esquecidas as diferenças em termos da escala de tempo na produção dos textos e suas condições particulares que envolvem formas de escrita distintas, conforme a mídia utilizada e a particularidade de injunções profissionais presentes (ou não) na sua produção.

Considerada tal diferença, há diversas formas de avaliar a relação entre a crítica e a pesquisa universitária, evoca-se, então, duas formas opostas de polarizar o jogo das quais discordo.

Primeiro, um exemplo de polarização vinda de um crítico.

No encontro "Écriture critique, état de veille", organizado por Jean Brechand, da revista Vertigo, no Moulin d'Andé Ceci-Centre des écritures cinématographiques, em março de 1999, tendo como convidados críticos e professores universitários, a primeira comunicação foi da pesquisadora Suzanne Liandrat-Guigues, da Universidade de Paris 3, tendo como objeto o cinema de Luchino Visconti; uma excelente análise 
de aspectos da obra do cineasta. Terminada a sua palestra, Jean-Michel Frodon, então crítico do jornal Le Monde, foi o primeiro a tomar a palavra no debate e iniciou sua fala com a frase "Isto não é crítica de cinema". Em seguida, expôs suas considerações sobre o ensaio acadêmico escrito a partir de uma distância no tempo, em contraste com o embate com as obras vivido pelo crítico. O acadêmico é figura cujo texto chega tarde, depois que a crítica atribuiu os valores, disse o que era preciso ser dito sobre cada filme, configurou cada uma das fases do cinema se posicionando de imediato e em sintonia com cada nova conjuntura presente, quando apontou tendências, incensou autores etc., tudo no calor da hora. Esse é o desafio maior, essencial. O restante não será crítica de cinema, será outra coisa, feita em condições confortáveis, tendo todo tempo do mundo. Nessa oposição radical, o teórico é a figura que requenta ideias, põe-se a pensar o já pensado dentro de novas molduras conceituais; o historiador é um revisor que acaba tendo de passar pela crítica que lhe antecedeu para montar seu ponto de vista. Liandrat-Guigues respondeu com a mesma aspereza, e o debate teve seus desdobramentos.

Considerada a posição de Frodon, no polo oposto teríamos a figura do professor-pesquisador que olha para a crítica como um posicionamento muito marcado pela circunstância, sem argumentação mais rigorosa e vago nos conceitos. Nessa perspectiva, a crítica seria opinião, ideologia, expressão de uma subjetividade sem método, não preocupada em demonstrar suas teses, uma elaboração que, por melhor escrita, estaria pautada pelo que, no campo da literatura, chegou a ganhar um nome: "impressionismo crítico".

A meu ver, o essencial é recusar essas duas faces da moeda de troca de hostilidade e preconceito. Num polo, a defesa da primazia do chegar primeiro e viver a zona de risco. No outro, a noção de que o valor estaria neste chegar devagar, porém supostamente mais bem armado, de modo a garantir a produção de algo mais consistente. A questão é outra. Dito de outra forma, essa primazia do chegar primeiro não é garantia de valor, e tudo o mais que virá depois é um espaço amplo de recriações e avaliações trazidas pelo próprio movimento da produção cinematográfica, que requer uma constante criação de pontes, modos de observação 
e avaliação. Ao mesmo tempo, inovações no campo conceitual do ensaio crítico são uma questão bem mais complexa do que simplesmente reformular juízos de valor, argumentos e percursos já feitos. Posto isso, vale acentuar também que esse chegar devagar, com a régua e o compasso do método tampouco garante valor, pois o percurso de um ensaio crítico, mesmo que amparado no método e no domínio das operações lógicas por este requeridas, pode ser curto em seus resultados por falta de percepções ou ideias impulsionadoras da parte de quem caminha apoiado em suas regras.

O ensaio de perfil acadêmico e a sistematização teórica do pesquisador são viagens que, sem dúvida, seguem, no momento de sua exposição, um roteiro que parece cumprir as etapas previstas de um método, mas em seu ponto decisivo - que é o embate com as obras que tomou como objeto de reflexão em sua singularidade - essa viagem se dá como uma busca por insights críticos originais, pontuada por problematizações sucessivas que vão compondo um movimento singular próprio a cada experiência individual, e não simplesmente a execução de operações prescritas pelas regras de determinada disciplina.

A crítica é uma experiência de crise, no sentido positivo, e demanda intuição, escolha e criação. Instrumentada? Sim, pois não subtrai método nem corpo conceitual em nenhuma de suas modalidades. No entanto, embora o pesquisador utilize procedimentos que podem ser partilhados e operações que se apoiam num método, faz-se presente um campo de percepções que depende de sua sensibilidade, imaginação, intuição e experiência pessoal.

Neste final de percurso, vale reiterar que a ênfase nas articulações e na permeabilidade que supõe o mesmo sujeito nos distintos modos da crítica tem como pressuposto a observância das condições próprias a cada situação. Claro que deve que ser vivo o diálogo entre o crítico profissional, o professor de cinema e, de modo geral, os historiadores, cientistas sociais e filósofos que pesquisam e escrevem sobre cinema. E há nítida convergência dos lugares de fala quando publicam na mesma revista ou em livro antologia, para além de toda a interação e dependência mútua para gestação de ideias, formulação de conceitos e escolha de estratégias 
que atingem o nervo das obras. Posto isso, críticos, ensaístas, pesquisadores e teóricos, de posse ou não de um impulso de inovação, devem operar de modo a responder de forma criativa as exigências próprias a cada desafio. Enfim, atravessar a zona de risco própria a seu métier.

\section{Referências}

AVELLAR, J. C. A ponte clandestina: teorias de cinema na América Latina. São Paulo: Editora. 34/Edusp, 1995.

BAZIN, A. O que é o cinema? São Paulo: Ubu, 2018.

CANUDO, R. L'usine aux images. Paris: Etienne Chiron, 1927.

DANEY, S. Ciné journal: 1981-1986. Paris: Cahiers du Cinéma, 1986.

DELEUZE, G. A imagem-movimento. Tradução: Stella Senra. São Paulo: Brasiliense, 1985.

DELEUZE, G. A imagem-tempo. Tradução: Eloísa de Araújo Ribeiro. São Paulo: Brasiliense, 1990.

DESNOS, R. Cinéma: textes reunis et présentés par André Techernia. Paris: Gallimard, 1966.

ELSAESSER, T; BARKER, A. Early cinema: space, frame, narrative. London: BFI Publishing, 1990.

EPSTEIN, J. Écrits sur le cinema. Paris: Seghers, 1974. t. 1. 
EPSTEIN, J. Bonjour cinéma. Paris: Éditions de la Sirène, 1921.

LEYDA, J. Kino: a history of Russian and Soviet film. London: Allen \& Unwin Pub, 1960.

LEYDA, J. Dianying/electric shadows: an account of the film audience in China. Cambridge: The MIT Press, 1972.

LINDSAY, V. The art of the moving picture. New York: Modern Library, 2000.

MACEDO, A. A evolução estética do cinema. Lisboa: Clube bibliográfico Editex, 1959.

MERLEAU-PONTY, M. O cinema e a nova psicologia. In: GRUNEWALD, J. L. (org.). A ideia do cinema. Rio de Janeiro: Civilização Brasileira, 1969. p. 101-118.

MUNSTERBeRG, H. Photoplay: a psychological study. New York: Dover Pub, 1970.

SITNEY, P. A. Visionary cinema. New York: The Oxford Press, 1974.

XAVIER, I. Sétima arte: um culto moderno: o idealismo estético e o cinema. 2 ed. São Paulo: Edições Sesc, 2017.

submetido em: 10 mar. 2019 | aprovado em: 20 abr. 2019 